\title{
Developing a Framework for Curriculum Evaluation in Oman
}

\author{
Khalid Salim Saif Al-Jardani \\ Curriculum Officer for English Language \\ Ministry of Education, Sultanate of Oman \\ $\&$ \\ $\mathrm{PhD}$ Student of University of Malaya, Malaysia \\ E-mail: kaljardani@hotmail.com
}

Received: November 17, 2012

Accepted: December 3, 2012

Published: December 4, 2012

doi:10.5430/elr.v1n2p73

URL: http://dx.doi.org/10.5430/elr.v1n2p73

\begin{abstract}
The field of curriculum evaluation is a key part of the educational process. This means that this area needs to be developed continuously and requires ongoing research. This study highlights curriculum evaluation in Oman, different evaluation procedures and methods and instruments used. The need for a framework for curriculum evaluation is a vital part of this research. A whole clear process of developing the framework using selected experts from different organisations including the Ministry of Education and national universities, colleges and institutes, who have the knowledge of both the English teaching context and the curriculum development and evaluation in Oman, is introduced. The research can be selected and agreed with the elements on a good basis for any other framework for the Omani context and even for other contexts
\end{abstract}

Keywords: Curriculum Evaluation, Developing a framework, Oman, Curriculum experts, Delphi method

\section{Introduction}

The field of Curriculum Evaluation is still being developed and when looking closely at the Curriculum Evaluation books and articles, it is clear that the aspects covered in this area are still insufficient if compared to other issues in Education. This important aspect of Curriculum Evaluation is vital and needs a great deal of work, especially in developing a systematic approach for Curriculum Evaluation in the long-term.

The educational system in Oman has been developed continuously. In 1998, a new system was created based on the new education philosophy which took into account the different stakeholders' needs and expectations as well as to cope with the changing world in sense of the information and skills needed and the technology utilized(Al-Jardani, 2012).

This research will only focus on English Language Curriculum Evaluation but not for that of other subjects. Developing a framework is expected to be beneficial for all parties. For example, in the English teaching context, having clear standards would help planners at the higher level of training, curriculum, supervision and assessment officers. This would also help practitioners in the field, such as teachers, to know what they are expected to do regarding curriculum evaluation and methods used to check what are being covered. It would also help the whole nation, such as parents, to know what has been covered and what kinds of support they need to offer. This supports the need to have and further develop a public framework for Curriculum Evaluation.

The lack of a framework for the public for Curriculum Evaluation in the Ministry of Education in Oman has been observed (Al-Jardani, 2011). This has resulted in a miscommunication between the curriculum departments and the practitioners in the field. Building and publicizing a framework helps to show the role and responsibility of each in developing and evaluating the curriculum.

\subsection{Research Question}

What Quality Standards (elements) of Curriculum Evaluation should be considered for the framework for Curriculum Evaluation? 


\section{Literature Review}

Different definitions of Curriculum Evaluation are found in the existing literatures about the topic. It can be defined as a systematic process for collecting and analyzing all relevant information for the purpose of judging and assessing the effectiveness of the curriculum to promote improvement (Nichols, et al. 2006; Simons, 1987 in Marsh, 2004: 106 and Brown, 1989: 223 in Brown, 1995: 218). The definition consists of key words such as systematic, process, collect and analyse, relevant information, curriculum effectiveness' assessment, and to improve.

Curriculum Evaluation can be either a small-scale task involving a very limited number of participants if it is classroom based, or a massive large-scale task involving a number of schools, teachers, parents, officers and some community members. An action research exercise conducted by a teacher in his/her class with learners can also be part of Curriculum Evaluation. On the other hand, an internal or external evaluator evaluating a whole curriculum covering several schools, a large number of teachers and learners, and which may additionally cover the schools' surroundings, may also constitute Curriculum Evaluation.

Different writers have developed guidelines for Curriculum Evaluation, but without developing a framework for Curriculum Evaluation or even systematic ways of record keeping. This issue will be highlighted in depth in the next section.

It is not easy to find common guidelines for Curriculum Evaluation; and it is difficult to find a suggested framework for Curriculum Evaluation. This could be only found as a section in the frameworks for general curricula. However, for my context and some other places where Curriculum Evaluation is treated as a dependent department, a need for separate Curriculum Evaluation is essential.

In the existing literatures as mentioned above, only some examples of curriculum framework have been observed. These normally consist of a rationale or platform, scope and sequence, aims, goals and purpose of subjects, guidelines for course design, teaching and learning principles, guidelines for evaluation of subjects, criteria for accreditation and certification of subjects and future developments for the area (Marsh, 2004: 21). Therefore, it has been noted that Curriculum Evaluation is only one factor in these frameworks. However, some of these elements can also be included in the Curriculum Evaluation framework such as rationale of the framework, scope and sequence of the curriculum, aims, and goals, purposes of each subject and future development of the area of Curriculum Evaluation. Other things which can be added are a vision and mission of the Curriculum Evaluation task and guidelines of Curriculum Evaluation theory and practices.

Some of the key issues when developing a framework are that a clear link needs to be developed between theory and practice, to make it easy to try things out. Another consideration is that the content needs to be up-to-date and contains relevant information about the area. In general it should include pedagogy, learning and resources (Marsh, 2004) as all of this helps to enrich teachers and other people who are interested in knowing about Curriculum Evaluation in the particular context.

There are a number of advantages and disadvantages that using a framework might have. Marsh (2004) stated some of the advantages.

- The curriculum will be more coherent and orderly.

- High-quality curriculum development is likely to occur because planning criteria and standards apply consistently across all curriculum frameworks.

- New content and skills can be easily accommodated in curriculum framework including various multidisciplinary and interdisciplinary variations

- Curriculum frameworks developed at a national level; have the potential to become accepted as national frameworks

- Better chances to add up some extra activities such problem-solving, higher-order thinking skills and others.

Here he also suggests some disadvantages of using curriculum frameworks:

- If they are too detailed they become very directive for teachers.

- They can become instruments of compliance used as a mean of control by central education authorities without considering differences of context.

This shows that developing and using frameworks has more advantages and it is very easy to overcome the disadvantages. This can be done by developing a simple and to-the-point document which should be developed in such a way to guide and support different participants. 
As little attention is given to developing a framework of quality standards for Curriculum Evaluation, the need to understand the complexity of the field of education is essential. A great deal of work has being done in the fields of higher education, health and business in this matter. This needs to cover school, curriculum, teacher training, curriculum development and evaluation and other areas of education.

\section{Method}

Based on this, this study will reflect a scientific perspective on research and use of Developmental Research. The Developmental Research process is normally cyclic or spiral: "analysis, design, evaluation and revision activities are iterated until a satisfying balance between ideals and realization has been achieved" (Akker, 1999: 7). This seems to be the most suitable research approach for such study. It also involves using the Delphi method. The Delphi method is a method in the form of a process involving individuals or experts in the field to work on a problem or issues using a series of data collection and analysis techniques (Skulmoski, et al. 2007).

The Delphi method, utilized in this research, is a group decision making technique. It seeks to achieve an agreement among group members through a series of questionnaires and interviews in some cases. The questionnaire is answered anonymously and individually by each member of the group, then the answers are summarized and sent back to the group members along with the next questionnaire. The process is repeated until a group agreement is reached. It is anticipated that this might take two rounds or more until agreement between members is reached. However, for this study a proposed of 3 rounds are planned unless more is needed. For this study, the method will start with interviewing the experts followed by 2 questionnaires, but this might continue with more questionnaires if needed.

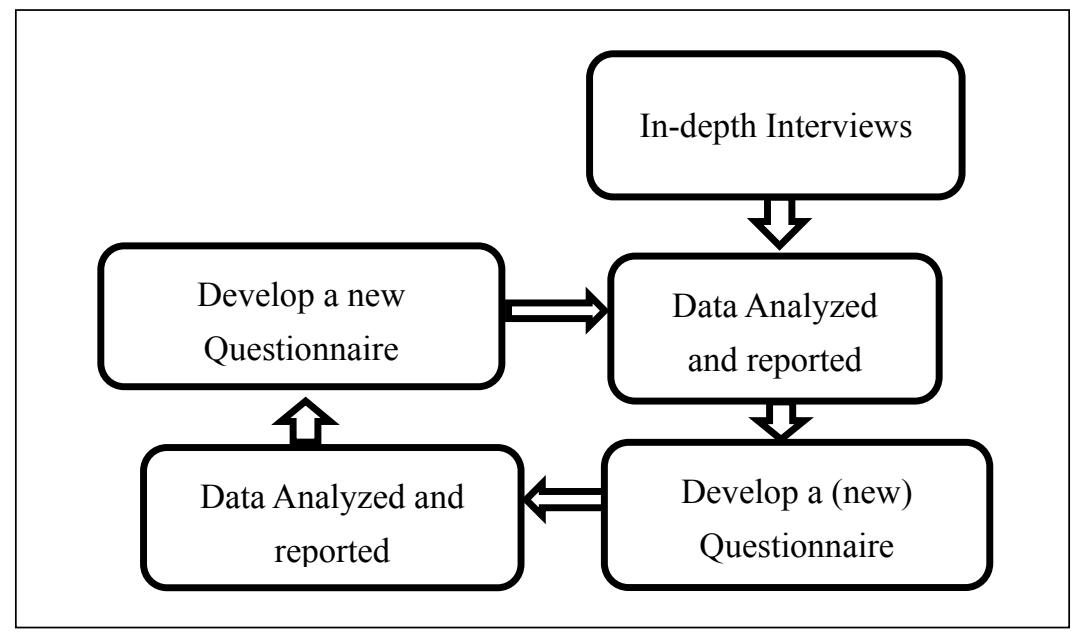

The Delphi Method

The Delphi method is usually used when face to face meetings are impossible because of geographic distance, or when some of the members have time issues. This study will use a computer-based version as it is not easy for the researcher and the experts to meet. However, a need for face-face interviews to discuss issues related to curriculum evaluation and what aspects should be covered in the framework. For questionnaires, emails as a mean of communicating with the experts is the way which can ensure a good communication with them although continuous reminders is essential to keep them in the research. Therefore, a complete information of each experts agreed to participate is needed to be included more than one email and contact numbers.

\section{Research instruments}

For Round 1, interviewing the experts should set the whole data collection stage. The question needs to get a good picture of what the framework can include. The questions covers how important is to have a framework, who will help if we have one and the effect of its absence, its target audience and the main questions is what aspects should be covered in the framework in order to answer the main research question (the interview questions in Appendix A).

In Round 2, Questionnaire 1 (Appendix B), the experts will be given the list of items suggested by themselves during the interviews. They rank them using a scale (from agree strongly to disagree strongly using five scales). There are space for them to add items to the suggested ones, and also a space for them to add any comments regarding designing and developing the framework. 
In Round 3, Questionnaire 2 (Appendix C), the experts are expected to put the items from questionnaire 1 in order. There is a space for them to write any other comments, which will be analysed qualitatively.

\section{The Participants}

Apart from being a specialist in curriculum and Curriculum Evaluation, selected experts should also have a reasonable practical experience of dealing with issues related to Curriculum Evaluation and other issues including knowledge and a willingness to participate in the current research.

Participants in this study are Curriculum and Curriculum Evaluation Experts. They represent both genders and have different qualifications and experience. Their agreement to take part in the study adds to the strength of it as they seem to be the most important individuals in the area of Curriculum in Oman.

All experts are holding a master or a $\mathrm{PhD}$ degree in the field of Education. This shows that they are qualified enough to do their job as curriculum and curriculum evaluation experts in different institutions including the Ministry of Education, colleges and universities. They have varies of years of experience in the field of Education which is between 14-41 years. This range of years might help to have varies and rich input. The master degree holders are supported with a rich experience in developing and evaluation curricular as well as in the sense of the years they spend in positions of ELT in different organisations.

This variety of genders, degree levels and years of experience will help to ensure a rich data collection. However, they are not planned to do research on these variables in this research. This could be kept for future reference. Moreover, in some cases where there is a need for participants' quotation, the sample of this study are 12 Curriculum Evaluation experts (EX1-EX12) in order to use their participants' actual words. Line numbers are also shown within them from the actual transcribed interviews. On the other hand and as stated above the sample used for the study was 12 participants out of about 20 invitations sent to all expected god collection of experts in Oman. Some of them apologized as they cannot see themselves covering the stated characteristics especially the clarity of the Omani curriculum contexts. Others also mentioned their own shortage of the understanding of the curriculum evaluation area because of long time working as administrators.

\section{Findings}

By using the Delphi method in this phase, this seeks to achieve an agreement among the participants in this case of the experts, through a series of questionnaires and interviews to answer the following research question: What Quality Standards (elements) of Curriculum Evaluation should be considered for the framework for Curriculum Evaluation? This study started with an interview followed by only two questionnaires where agreement on the elements and order of them for the framework was reached.

Here is a detailed analysis of the three rounds and different quantitative and qualitative data collected.

The three rounds will be ended by the findings of study. The findings addresses the change of the elements suggested in both the titles and the order of them as seen by the experts.

\section{Round 1}

The participants, the curriculum Evaluation experts agreed on the importance of developing a framework for Curriculum Evaluation and that it's the Ministry's role to develop one. "The ministry is responsible for all aspects of education, including developing curriculum. A framework that accurately and comprehensively evaluates implementation and outcomes is a vital part of the process (EX11 lines 3-6)". This seems to go along with the officers' point of view. The need for this seems to be vital.

Others specify the period in which a framework needs to be revised as, "between 5 and 10 years (EX5 line 13)". This as they say to help to identify recent needs of learners and jobs too. The period suggested between 5-10 years is also a chance for argument as what issues were considered to give exact years of trying out a framework which can cover most of the curriculum evaluation elements.

Another added that by having a clear evaluation, this will basically checks the ministry's objectives in terms of academia are achieved. These objectives must be checks and balances in anything as important as curriculum, as "it's developed; it is introduced, and is implemented (EX3 line 11)". As it was written-the curriculum-, learning outcomes and general goals and specific goals were written, therefore, how the ministry will know that it has achieved its objectives, that the goals set were met" questioned by (EX 8 line 6-10). This seems to be the most direct response of participants ended with a clear question of what can tell the ministry that it is doing a good task. By having a clear objectives and working towards achieving them is an important issue from the participants' point of view. 
It is agreed by participants that the framework would benefit all stakeholders: policymakers, curriculum officers, teachers and students. Others (EX 2, 3, 4, 9, 10 and 12) add teacher trainers and parents to the list. This seems to cover all people involved in the task of English Language Teaching in the target context. Involving parents is also important as stated.

Obviously the people given the responsibility to develop the curriculum, because they can then "modify, change, alter as and when the need is perceived to change (EX00 line 19) ". This specifies only the people working directly in developing and evaluating the curriculum as seen as the main users of the framework. They are basically the ones who write the curriculum based on their understanding of the learners needs and age interest. They also consider the society needs in order to reach their expectations.

The evaluation framework needs to take into consideration the needs of all stakeholders, and should be designed to benefit all of them as well. This covers also different organisations both the academic ones such as colleges and institutes but also the workplace.

All participants see the effect of the absence of curriculum evaluation on the curriculum itself. Simply they say as EX4 (lines 27-30) stated that "if there is no curriculum evaluation, then obviously the ministry will not know if they are on the right path, whether the goals lobjectives set were attainable, and if not why not?" This support the rationale of the study as this seems to clarify the miscommunication between different parties related to the English Language teaching in the target context.

A curriculum evaluation document will not only help in the collecting of data, but also check whether different schools are able to achieve. This includes "urban /rural schools boys versus girls, as there may be different results based on calibre of teachers"(EX 1 lines 25-26), area where school is situated and other factors. These factors as suggested by an expert need to be addressed within the document. The issue of developing a curriculum or even a framework for each region which might have different needs and learners of it have different interest. Use of English in the Kuala Lumpur is different in another state in both the exposer and the chance to use it in daily life. The question is how easy to cover these within a curriculum or even in a framework of curriculum evaluation.

To summarise one of the participants says that "without a workable curriculum evaluation framework, it would not be possible to know directly the effects of the curriculum"(EX5 lines 22-23). Moreover, this absentee might affect even the teaching effort utilised by the teacher as for example he/she is using methods which does not suites the curriculum developed and the underlying principles of English teaching in the country.

The participants agree that the framework should evaluate every aspect of curriculum design, implementation and outcomes. This covers different levels of curriculum. That should include the goals and objectives themselves; skills and information; material used; presentation of the material by teachers; teacher training; what students experience and their reactions; student assessment both formative and summative evaluation; and how these accord with ministry goals and policy.

Here are the main findings from round 1 :

Elements suggested for the framework for Curriculum Evaluation

The previous findings will not be developed within the Delphi method in order to be developed within rounds 2 and 3. Therefore, the following findings which is only on the elements suggested for the framework will be utilized for the coming rounds.

Participants highlighted different elements which can be part of the framework. These elements are shown in the table below- more details of the elements are in appendix D.

Insert Table 1 here

The participants show agreement with most of the listed items. All of them mentioned most of the items except the mission and vision and the need for a section for setting a communication between different departments dealing with English Language Teaching. The Instruction Time (EX 2, 4, 5, 6, 8, 9, 11 and 12) and the Management \& Evaluation element (EX 2, 4, 5, 6, 8, 9 and 12) were highlighted only by a number of them as well as the communication one (EX 4, 6 and 12). The difference between participants helped to make a long list of elements which can be developed later.

However, the list above was mentioned by most of the participants during the interview. In some cases they might use a different term to articulate the same thing, such as teaching materials instead of resources and educational aids. These differences in terminologies might depend on personal experience and the place they work in at the moment. 
The list from table 1 is used as a basis for the framework in the questionnaire build for round 2. The list above is used for round 2 and experts have also a chance to add to the list if necessary as there is a space to add more elements.

\section{Round 2}

This round consists of a questionnaire to rank the suggested elements from round 1, add to them or drop the unnecessary ones for the framework. This questionnaire and the followed ones, the section will start with an analysis of the number of items included within it, the reliability and the validity before presenting the findings of the round.

\section{Insert Table 2 here}

The questionnaire contains 18 items suggested by different experts during the interviews in round 1 . The same experts in this round evaluate them according to the extent to which they agree with having them in the suggested framework.

The value for reliability coefficients for the questionnaire is 0.796 shows that it almost has a very good reliability. The validity of the questionnaire is 0.892 which refers to the accuracy of an assessment. This was calculated as the square root of the reliability coefficient. This shows that the questionnaire is also valid in this case. There weren't any added items to the list from the participants so the list is kept for the third round for ordering.

\section{Insert Table 3 here}

Using interquartile analysis shows that the responses are at higher level. Looking carefully in to the table shows most of is zero as there is no clear difference between the responses. Therefore, more focus is given to analysing the mean as it seems to show to what extent participants agree with having the elements in the framework.

From the table above, the mean and the median of each item are high and for the mean it is ranged between 4.0 and 5.0. This shows that participants are almost agree with including all the elements in the list. The most needed items are items 4 and 7, as all members of the whole sample see them as the most needed items to be included in the framework. It is also notice that half of respondents at least agreed strongly with all the items which support the above discussion.

On other hand, only one participant disagrees strongly with an element which is the Stakeholders' needs and expectations element. However, this not supported by other participants, although that element is also the least mean compared to other elements.

Studying the mean and the standard deviation of each item shows the degree of agreement for each one is high. This highlights the importance of including all the suggested items from the experts' point of view. Therefore, a decision of keeping the entire list for the next round is reasonable.

Agreement on the list of elements

Round 2 data analysis emphasis the list produced in round 1. Participants seem to be happy with the list without adding or dropping from it during this round. The high level of agreement noticed from the mean, median, standard deviation and the interquartile range. There is no doubt that this list will be put as it's in the questionnaire for round 3 . The coming round will make sure that all of the participants happy with the list as well as a chance to get a reasonable order of these elements.

Planning the new questionnaire

In order to plan the round 3, it seems that the order of the element task is the key thing. Therefore, the questionnaire will include all the elements and a space for the participants to put a number next to them, next to that there is a need to have a space for them to write any comment related to that specific elements when developing it later. Moreover, an empty box provided at the end of the questionnaire for any general comments regarding developing the framework in general.

Round 3

In this round a questionnaire is used for the experts to put the elements from round 2 in order. There is a space for them to write any other comments, which are analysed qualitatively.

\section{Insert Table 4 here}

Similar to the previous questionnaire, the questionnaire also contains 18 items. The same experts in this round put the items or the elements in order. The reliability for the questionnaire is 0.624 by using Cronbach's Alpha, which 
shows that it also has a very good reliability. As Validity refers to the accuracy of an assessment; it's 0.790 . There weren't any added items to the list from the participants even in this questionnaire.

\section{Insert Table 5 here}

Using interquartile analysis shows clear differences of the participants' responses which was not clear in round 2. It mainly helps to provide a possible location of each item. On the Other hand, working on the mean for each item seems to be the most useful thing for developing a reasonable order of the items. The order based on the mean seems to be more reasonable. However, for the order 1 and 2 for example and when the mean is the same, the difference in the standard deviation is used. The same thing works for elements 12 and 13.

The table above shows almost the analysis of the questionnaire. However, the researcher intends to use mainly the mean as it helps with getting a reasonable order based on the participants' responses.

A clear issue comes out of this analysis of round 3 that this seems to be the most argued point for the experts. Looking back at the mean of round 2 questionnaire, it was clear that they were almost agreeing with the importance of the elements, however, in this case it looks like they have a different views of the order of the these elements within the proposed framework.

A short list of elements

Analysing the comments by some participants qualitatively, they feel that "some of these elements are too similar to rank separately (EX 2: general comments) and EX5 says that "... one and two in my opinion go together (general comments)" .This was supported by other participants including EX 4, 5, 7, 9, 10, 11 and 12.

The elements suggested by the experts and the also their order are as follows:

1. Rationale and Policy of the Ministry of Education

2. Vision of the Curriculum Evaluation in the Ministry of Education:

3. Mission of the Curriculum Evaluation in the Ministry of Education

4. Stakeholders' needs and expectations

5. Aims and learning objectives and outcomes:

a. Aims \& Objectives

b. Learning Outcomes

c. Skills \& Sub-skills

d. Language Items

This section is suggested to cover the four issues. A clear plan to cover all of these within one section is important.

6. Linguistic and non-linguistic objectives

7. Methods \& Approaches

a. Methods \& Approaches

b. Learning and Curriculum theories adopted

This section also covers the two elements within the framework.

8. Textbooks \& Materials

9. Resources

10. Instruction Time

11. Assessment

12. Teacher Training

13. Management \& Evaluation

On the other hand, element 18, in the previous list, (communication) should go on throughout the whole process "I feel this goes on throughout the whole process EX 7 (communication specific comment)" and that there no need to have it separated suggested by a number of the participants. This can help in developing a short list like this which can be developed later. 
This answers the research question: What Quality Standards (elements) of Curriculum Evaluation should be considered for the framework for Curriculum Evaluation? However, a need for filling in the content for the proposed framework In the coming section, analysis of the available documents is worked out to develop the framework.

A completed proposed framework

There is a need to analyse different documents in order to develop the first draft of the Framework for Curriculum Evaluation. In order to develop the framework, the following documents were analysed:

- The English Language Curriculum Framework published by the English Section in the Human Sciences Department.

- $\quad$ The Student Assessment Handbook for English Documents from the Curriculum Evaluation Department related to English Language

- The Professional Development Plan for 2011 published by the Teacher's training Department.

- The General Framework of the curricula in the Sultanate of Oman, unpublished document by Curriculum Evaluation Department

The documents available can cover most of the items suggested for the framework. However, there is a need to analyse them and choose the content to be included in each elements.

Analysing the available documents could cover almost most of the needed elements to build the first draft of the framework. However, the section on curriculum evaluation still needs general information about curriculum evaluation issues. However, aspects related to curriculum evaluation is almost missing within the documents, so one of the researcher papers on the topic titled as 'The need for developing a Framework for Curriculum Evaluation' published in the Proceedings of ICERI2011 Conference in Madrid, Spain (Al-Jardani, 2011) is also used. This article covers most of the general issues and up-to date information on curriculum evaluation in general and in Oman. The article was written during the study in order to cover the missed content of the elements:

- Curriculum Evaluation

- The purpose of curriculum evaluation

- Who should be involved?

- Gathering the information

- The result of evaluation

- $\quad$ Record keeping

By using the article it almost that all elements suggested by the experts are covered and that a draft of the framework is ready.

Based on the above analysis of the documents, a complete draft framework is developed. There are 13 sections included as stated above. Each section covers the suggested element. For each section, a detail of issues is covered as follows:

The framework starts with an introduction covers the main issues and the main terminologies definition used within the document.

1) Rationale and Policy of the Ministry of Education

This covers the rationale beyond teaching English in Oman. This covers the expected changes in educational philosophy, the role of English in the society, students' and parents expectations, and increasing level of students of the knowledge of outside world, students' awareness and change of educational technology.

2) Vision of the Curriculum Evaluation in the Ministry of Education

This covers the vision of the curriculum evaluation departments.

3) Mission of the Curriculum Evaluation in the Ministry of Education

This section highlights the mission of the department too.

4) Stakeholders' needs and expectations

This covers the use of English in Oman in different parties and the expectations of employers, higher education institutes, parents and the society in general. 
5) Aims and learning objectives and outcomes:

This seems to be a long section as it covers the general learning objectives for the three levels of schools (Basic Education Cycle 1: grades 1-4, Basic Education Cycle 2: Grades 5-10 and Post Basic Grades 11 and 12). It also covers the learning outcomes for the same levels. This section ends with specific objectives of different levels too. This covers different skills and strategies intend to be developed for each level of schools.

6) Linguistic and non-linguistic objectives

This section covers two main issues, the linguistic and the non-linguistic objectives. In the linguistic objective part, vocabulary, grammar, and the four skills (Reading, writing, listening and speaking skills) are covered in the sense the methods used to use them within the curriculum.

The non- linguistic objectives cover the culture, learning strategies, and attitudes and motivation. How these objectives are tackled in discussed within this section.

7) Methods \& Approaches

This highlights the methods and the approached utilized within both syllabus, the English for me (grades 1-10) and the Engage with English for grades 11 and 12.

8) Textbooks \& Materials

In this section, a description of the curriculum is provided and also point out and highlight the components of the English Language Curriculum in Oman.

9) Resources

This section presents some useful online resources covering different aspects which teachers and other can use. This covers searching, Internet guides and resources, crossword puzzle makers, poetry, journals, references, story telling, publishers, pronunciation, writing, teacher training, and organisation.

10) Instruction Time

This section covers the instruction time- number of periods for English subject. This cover grades 1-12.

11) Assessment

The assessment section highlights two main issues. These are the weighting of each element including the four skills and their weight within the continuous assessment (daily assessment through observation), Class test and the end of semester test. The other issue presented within the section is the mark grades and their remark. This starts with $90 \%$ $100 \%$ as Excellent to $49 \%$ and less as need future support.

12) Teacher Training

This section covers the key aspect of in-service teacher training and courses covered within the training department.

13) Management \& Evaluation

This is also a long section, as it covers different subtitles related to Curriculum evaluation. This includes the purpose of curriculum evaluation, who should be involved, gathering the information, the result of evaluation and record keeping for the process of curriculum evaluation

The document ends with a list of references used for developing the framework.

\section{Conclusions}

As there are three rounds within this study, separated discussion of the findings is also done. These three rounds intend to give an answer to the following question as stated in chapter 1 of this study: What Quality Standards (elements) of Curriculum Evaluation should be considered for the framework for Curriculum Evaluation? Therefore, the focus will be mainly on what the finding can provide in order to answer it. Round 1 has given a focus on the following issues based on the questions from the interview.

The importance and the argent need of having a framework for curriculum evaluation is clear from the experts' responses. The framework is seen by experts as a guide of the process of the evaluation and helps to make sure that objectives are achieved. On the other hand the framework needs to be developed and checked regularly.

Apart of the officers list of the audience, who the framework can help, the experts specify the term 'stakeholders'. This includes all the suggested ones from the officers, in addition they also adds 'parents' as an audience too. The 
word' stakeholders can also include job makers and higher education institute which was not mentioned in the officers interviews.

The framework is expected to be workable that help to assess the effectiveness of the curriculum. It should covers evaluating the curriculum in different areas in the Sultanate. modern, remote schools, desert, coast and schools in mountains. This need to to need different needs and interest and whether they are met in the curriculum.

The aspects of curriculum were almost mentioned as well as other issues related to English Language teaching. This also covers teacher training and students assessment and basically all input given to teachers.

The 20-30 minutes of interview with the experts was useful to come up with a good list of elements for the framework. The interviews were used to best in identifying the list. The list covers three side of the framework. The policies, vision, mission, and theories whatever form the basis of the curriculum: its underlying structure and the rationale behind developing it in the way it is developed. The second side is the evaluating the specific of the curriculum such as course components and third side is other aspects including the assessment and the teacher training issues.

For round 2 findings which was in a form of a questionnaire shows a number of issues which will be highlighted.

As the questionnaire only contains 18 items, that was easy to develop and manage. It seems that the number of items helped to encourage participants to do it fast and to get filled ones from all participants. This helped to have a very reliable and valid one. A very good reliable and valid questionnaire drives a good result of it. A good analysis of the interview in round one helped to get into a very agreed list of items which easily can included in the framework.

The experts seem to be agreed with what they point out individually in round 1 . This shows that they are certain with what the framework should include based on their experiences. The stakeholders' item is the most argued item is the questionnaire. The huge expectation of the items seems has affected some of the experts to choose, as it got the only strongly disagrees point. However, even with this, still the responses were highly positive towards the elements.

Studying the findings of round 3 in general, it seems that they quite agreement in both round 1 and 2 seems to be different in round 3. Although participants were strongly agreed with most items in round 2, this seems different in round 3. The responses were varies and ranked. For round 3, the second questionnaire, it focuses mainly on the order of the suggested elements. Using different types of analysis helps to get into better way to analyse data. This shows the need to use different types such as analysing different statistics including the mean, standard deviation, the direction of each element, the interquartile analysis, median, mode, the minimum, the maximum and the Anova if necessary in order to develop a reasonable, reliable and valid data.

As one of the main findings of round 3 was to reduce the number of items, this helped to give more focus on each item in the framework and also avoid repetition. This seems to be useful to the users of the framework, curriculum officers, and policy makers in the Ministry and also the senior supervisors who are observing and supporting both supervisors and teachers to cope with the curriculum.

Most information needed for the framework is available, but can only be found in different documents. This makes it difficult for the Curriculum Officers to find information when needed. A document which covers all aspects related to English Language Curriculum Evaluation is essential. This also supports the need for this proposed framework.

Here are some other issues related to each document analysed. The existing Curriculum Framework contains some of the items suggested for the Curriculum Evaluation Framework. It is a good source of items directly to curriculum development in Oman. However, as mentioned above, most issues related to curriculum evaluation cannot be found in this document.

There is a need for having the learning outcomes for each grade as there are also not seen in the curriculum framework. They are only mentioned in the assessment document for each level and only for joined grades. The need for identifying the learning outcomes based on the objectives of each grade is vital for the future curriculum development and evaluation.

The weighting of each skill and for each level helps teachers to give different level of focus in order to achieve the learning outcomes which supposed to be shown clearly. This highlights the need to work cooperatively with the curriculum department to develop both the learning outcomes and the weighting of each skill for each grade.

A general overview of the training issues will only be added to the framework and a note of that there is a need for key aspects of curriculum evaluation need to be addressed. This would encourage and support teachers in their role in curriculum evaluation. This was missed from the training document. However, there is an argument between the curriculum officers and the experts regarding including the training issue in the curriculum evaluation framework, 
but they seem to agree with the need to involved issues related to curriculum evaluation within the training document and their programme too. A need to produce a framework for curriculum evaluation as the department were found in 2006 and an argent need to publish one is important. It seems that the proposed framework can be a good basis for future framework.

\section{References}

Akker, J. (1999). Chapter 1: Principles and Methods of Development Research in Akker, J., Branch, R.M, Gustafson, K, Nieveen, N and Plimp, T. (1999) Design approaches and tools in education and training. Netherlands: Kluwer Academic Publishers.

Al-Jardani, K. S. (2011). The need for developing a Framework for Curriculum Evaluation. Proceedings of ICERI2011 Conference.14th-16th November 2011, Madrid, Spain. ISBN: 978-84-615-3324-4.

Al-Jardani, K. S. (2012). English Language Curriculum Evaluation in Oman. International Journal of English Linguistics. Vol. 2 No. 5 (ISSN 1923-869), E- ISSN 1923-8703).

Brown, J.D. (1995). The Elements of Language Curriculum. A Systematic Approach to Program Development. Heinle and Heinle Publishers: Boston.

Kennedy, C. (1987). "Innovating for a change: teacher development and innovation". ELT Journal Volume 41/3 July 1987. Oxford University Press. http://dx.doi.org/10.1093/elt/41.3.163

Marsh, C. (2004). Key Concepts for Understanding Curriculum. $3^{\text {rd }}$ edition. Routledge Falmer: London and New York.

Nichols, B, Shidaker, S, Johnson, G. and Singer, K. (2006). Managing Curriculum and Assessment. A Practitioner's Guide. Linworth Books: Ohio.

Skulmoski, G, Hartman, F. and Krahn, J. (2007). The Delphi Method for Graduate Research. Journal of Information Technology Education. Volume 6, 2007.

Table 1. List of elements suggested by the experts in round 1

\begin{tabular}{|l|l|}
\hline Elements & No. Experts \\
\hline Mission of the Curriculum Evaluation in the Ministry of Education & 12 \\
\hline Vision of the Curriculum Evaluation in the Ministry of Education & 12 \\
\hline Rationale and Policy of the Ministry of Education & 12 \\
\hline Aims \& Objectives (Goals) & 12 \\
\hline Linguistic and non-linguistic objectives & 12 \\
\hline Stakeholders' needs and expectations & 10 \\
\hline Learning Outcomes & 10 \\
\hline Learning and Curriculum theories adopted- Syllabus Type & 10 \\
\hline Language Items & 10 \\
\hline Skills & 9 \\
\hline Assessment & 9 \\
\hline Resources & 9 \\
\hline Teacher Training & 9 \\
\hline Textbooks \& Materials & 9 \\
\hline Methods \& Approaches & 9 \\
\hline Instruction Time & 8 \\
\hline Management \& Evaluation & 7 \\
\hline $\begin{array}{l}\text { Communication between different departments (Curriculum, } \\
\text { assessment, training, supervision, teachers, .. etc. of English Language) }\end{array}$ & 3 \\
\hline
\end{tabular}

Table 2. Reliability coefficient and validity of Round 2

\begin{tabular}{|l|l|}
\hline No. of items & 18 \\
\hline Reliability coefficient & 0.796 \\
\hline Validity & 0.892 \\
\hline
\end{tabular}


Table 3. The Mean, Median, Standard Deviation and the Interquartile range of Analysis of Round 2

\begin{tabular}{|l|l|l|l|l|l|}
\hline No. & Items & Mean & Median & Std. Deviation & Interquartile range of Analysis \\
\hline $\mathbf{1}$ & Mission & 4.83 & 5.00 & 0.39 & 0.00 \\
\hline $\mathbf{2}$ & vision & 4.83 & 5.00 & 0.39 & 0.00 \\
\hline $\mathbf{3}$ & Rationale & 4.83 & 5.00 & 0.39 & 0.00 \\
\hline $\mathbf{4}$ & Aims & 5.00 & 5.00 & 0.00 & 0.00 \\
\hline $\mathbf{5}$ & Linguistic \& non-linguistic & 4.75 & 5.00 & 0.62 & 0.00 \\
\hline $\mathbf{6}$ & Stakeholders & 4.00 & 4.50 & 1.35 & 1.75 \\
\hline $\mathbf{7}$ & Outcomes & 5.00 & 5.00 & 0.00 & 0.00 \\
\hline $\mathbf{8}$ & theories & 4.42 & 4.50 & 0.67 & 1.00 \\
\hline $\mathbf{9}$ & Language & 4.50 & 5.00 & 1.00 & 0.75 \\
\hline $\mathbf{1 0}$ & Skills & 4.58 & 5.00 & 0.90 & 0.75 \\
\hline $\mathbf{1 1}$ & Assessment & 4.83 & 5.00 & 0.58 & 0.00 \\
\hline $\mathbf{1 2}$ & Resources & 4.42 & 5.00 & 1.00 & 1.00 \\
\hline $\mathbf{1 3}$ & Teacher Training & 4.67 & 5.00 & 0.65 & 0.75 \\
\hline $\mathbf{1 4}$ & Materials & 4.75 & 5.00 & 0.62 & 0.00 \\
\hline $\mathbf{1 5}$ & Methods & 4.83 & 5.00 & 0.39 & 0.00 \\
\hline $\mathbf{1 6}$ & Instruction T & 4.75 & 5.00 & 0.45 & 0.75 \\
\hline $\mathbf{1 7}$ & Management & 4.75 & 5.00 & 0.45 & 0.75 \\
\hline $\mathbf{1 8}$ & Communication & 4.50 & 5.00 & 1.00 & 0.75 \\
\hline
\end{tabular}

Table 4. Reliability coefficient and validity of Round 3

\begin{tabular}{|l|l|l|}
\hline No. of Items & Validity & Reliability coefficient \\
\hline 18 & 0.790 & .624 \\
\hline
\end{tabular}

Table 5. The Mean, Median, Standard Deviation and the Interquartile range of Analysis of Round 3

\begin{tabular}{|l|l|l|l|l|l|}
\hline $\begin{array}{l}\text { The order based } \\
\text { on the Mean }\end{array}$ & Items & Mean & Median & $\begin{array}{l}\text { Std. } \\
\text { Deviation }\end{array}$ & $\begin{array}{l}\text { Interquartile } \\
\text { range of } \\
\text { Analysis }\end{array}$ \\
\hline 1 & 3: Rationale & 3.08 & 3.00 & 2.50 & 2.00 \\
\hline 2 & 2.Vision & 3.08 & 2.50 & 2.64 & 1.00 \\
\hline 3 & 1. Mission & 3.33 & 2.50 & 2.96 & 1.75 \\
\hline 4 & 6. Stakeholders & 4.67 & 4.00 & 4.08 & 2.25 \\
\hline 5 & 4. Aims \& Objectives & 4.75 & 5.00 & 1.29 & 2.00 \\
\hline 6 & 7. Learning Outcomes & 5.33 & 6.00 & 2.67 & 5.00 \\
\hline 7 & $\begin{array}{l}\text { 5. Linguistic and } \\
\text { non-linguistic objectives }\end{array}$ & 8.67 & 8.00 & 2.71 & 4.25 \\
\hline 8 & 8. curriculum theories & 8.92 & 8.50 & 2.19 & 2.00 \\
\hline 9 & 15. Methods \& Approaches & 9.50 & 9.00 & 3.18 & 6.00 \\
\hline 10 & 10. Skills \& Sub-skills & 9.92 & 11.00 & 3.78 & 5.00 \\
\hline 11 & 14. Textbooks \& Materials & 10.00 & 11.00 & 3.28 & 3.50 \\
\hline 12 & 9. Language Items & 11.00 & 10.50 & 2.45 & 3.50 \\
\hline 13 & 12. Resources & 11.00 & 12.50 & 2.80 & 4.00 \\
\hline 14 & 16. Instruction Time & 12.83 & 14.50 & 3.76 & 7.25 \\
\hline 15 & 11. Assessment & 13.25 & 14.00 & 3.72 & 3.75 \\
\hline 16 & 13. Teacher Training & 14.00 & 15.00 & 4.09 & 1.00 \\
\hline 17 & $\begin{array}{l}17 . \text { Management \& } \\
\text { Evaluation }\end{array}$ & 15.58 & 17.00 & 3.03 & 2.50 \\
\hline 18 & 18. Communication & 16.00 & 18.00 & 3.81 & 1.75 \\
\hline
\end{tabular}




\section{APPENDIX A \\ DATA COLLECTION INSTRUMENTS \\ Round 1: Interview Questions}

\section{Developing a Framework of Quality Standards for Curriculum Evaluation}

This interview will answer this specific question as Round 1 of the research:

- What Quality Standards (elements) of Curriculum Evaluation should be considered for the framework for Curriculum Evaluation?

- In what order should these standards be organised and why?

\begin{tabular}{|l|l|}
\hline Name: & \\
\hline Gender: & \\
\hline Qualification: & \\
\hline Job Title: & \\
\hline Work place & \\
\hline $\begin{array}{l}\text { Years of experience in } \\
\text { Curriculum filed }\end{array}$ & \\
\hline $\begin{array}{l}\text { Years of experience in } \\
\text { Education filed }\end{array}$ & \\
\hline Date: & \\
\hline
\end{tabular}

1. How important in developing a framework for Curriculum Evaluation is for Ministry of Education in Oman?
a. Who will it help?
b. What would be the effect of its absence?
c. Other aspects?

2. Who should it be written for?
a. Teachers
b. Students
c. Curriculum Officers
d. Policy makers
e. Others

3. What aspects should be covered within the framework?
a. Theoretical and practical issues related to curriculum and curriculum evaluation
b. Stakeholders roles and needs
c. Teacher training and professional development
d. Student assessment
e. Aims, objectives, and future direction
f. Ministry policy
g. Internal/external evaluation
h. Others 


\section{APPENDIX B \\ DATA COLLECTION INSTRUMENTS \\ Round 2: Questionnaire}

Developing a Framework of Quality Standards for Curriculum Evaluation

This questionnaire will answer this specific question as Round 2 of the research:

- What quality standards (elements) of curriculum evaluation should be considered for the framework for curriculum evaluation?

\section{Name:}

Date:

A. The following items are suggested by different experts. How far do you agree with including them in the Framework for Curriculum Evaluation?

\begin{tabular}{|c|c|c|c|c|c|c|}
\hline Item & $\begin{array}{l}\text { Agree } \\
\text { Strongly } \\
\end{array}$ & Agree & $\begin{array}{l}\text { Not } \\
\text { sure }\end{array}$ & Disagree & $\begin{array}{l}\text { Disagree } \\
\text { Strongly } \\
\end{array}$ & Suggested Details \\
\hline \multicolumn{7}{|c|}{$\begin{array}{l}\text { Mission of the Curriculum } \\
\text { Evaluation in the Ministry of } \\
\text { Education }\end{array}$} \\
\hline \multicolumn{7}{|l|}{$\begin{array}{l}\text { Vision of the Curriculum } \\
\text { Evaluation in the Ministry of } \\
\text { Education }\end{array}$} \\
\hline \multicolumn{7}{|l|}{$\begin{array}{l}\text { Rationale and Policy of the } \\
\text { Ministry of Education, }\end{array}$} \\
\hline \multicolumn{7}{|l|}{ Aims \& Objectives (Goals) } \\
\hline \multicolumn{7}{|l|}{$\begin{array}{l}\text { Linguistic and non-linguistic } \\
\text { objectives (Standards) }\end{array}$} \\
\hline \multicolumn{7}{|l|}{$\begin{array}{lll}\begin{array}{l}\text { Stakeholders' needs } \\
\text { expectations }\end{array} & \text { and } \\
\end{array}$} \\
\hline \multicolumn{7}{|l|}{ Learning Outcomes } \\
\hline \multicolumn{7}{|l|}{$\begin{array}{l}\text { Learning and Curriculum } \\
\text { theories adopted-Syllabus Type }\end{array}$} \\
\hline \multicolumn{7}{|l|}{ Language Items } \\
\hline \multicolumn{7}{|l|}{ Skills \& Sub-skills } \\
\hline \multicolumn{7}{|l|}{ Assessment } \\
\hline \multicolumn{7}{|l|}{ Resources } \\
\hline \multicolumn{7}{|l|}{ Teacher Training } \\
\hline \multicolumn{7}{|l|}{ Textbooks \& Materials } \\
\hline \multicolumn{7}{|l|}{ Methods \& Approaches } \\
\hline \multicolumn{7}{|l|}{ Instruction Time } \\
\hline \multicolumn{7}{|l|}{ Management \& Evaluation } \\
\hline \multicolumn{7}{|l|}{$\begin{array}{l}\text { Communication between } \\
\text { different departments } \\
\text { (Curriculum, assessment, } \\
\text { training, supervision, teachers, .. } \\
\text { etc. of English Language) }\end{array}$} \\
\hline & & & & & & \\
\hline & & & & & & \\
\hline & & & & & & \\
\hline & & & & & & \\
\hline
\end{tabular}

B. You can add some more comments here regarding designing and developing the framework.

Comments: 


\section{APPENDIX C \\ DATA COLLECTION INSTRUMENTS \\ Round 3: Questionnaire}

Developing a Framework of Quality Standards for Curriculum Evaluation

This questionnaire will answer this specific question as round 3 of the research:

- What Quality Standards (elements) of Curriculum Evaluation should be considered for the framework for Curriculum Evaluation?

- In what order should these standards (elements) be organised and why?

\begin{tabular}{|c|c|c|}
\hline \multicolumn{3}{|l|}{ Name: } \\
\hline \multicolumn{3}{|l|}{ Job Title: } \\
\hline \multicolumn{3}{|l|}{ Gender: } \\
\hline \multicolumn{3}{|l|}{ Occupation } \\
\hline \multicolumn{3}{|l|}{ Work place } \\
\hline \multicolumn{3}{|l|}{ Date: } \\
\hline Items & $\begin{array}{l}\text { Suggested Order } \\
\text { (Numbers 1-18) }\end{array}$ & Comments \\
\hline \multicolumn{3}{|c|}{$\begin{array}{l}\text { Mission of the Curriculum Evaluation in the Ministry of } \\
\text { Education }\end{array}$} \\
\hline \multicolumn{3}{|l|}{$\begin{array}{l}\text { Vision of the Curriculum Evaluation in the Ministry of } \\
\text { Education }\end{array}$} \\
\hline \multicolumn{3}{|l|}{ Rationale and Policy of the Ministry of Education, } \\
\hline \multicolumn{3}{|l|}{ Aims \& Objectives (Goals) } \\
\hline \multicolumn{3}{|l|}{ Linguistic and non-linguistic objectives (Standards) } \\
\hline \multicolumn{3}{|l|}{ Stakeholders' needs and expectations } \\
\hline \multicolumn{3}{|l|}{ Learning Outcomes } \\
\hline \multicolumn{3}{|l|}{ Learning and Curriculum theories adopted- Syllabus Type } \\
\hline \multicolumn{3}{|l|}{ Language Items } \\
\hline \multicolumn{3}{|l|}{ Skills \& Sub-skills } \\
\hline \multicolumn{3}{|l|}{ Assessment } \\
\hline \multicolumn{3}{|l|}{ Resources } \\
\hline \multicolumn{3}{|l|}{ Teacher Training } \\
\hline \multicolumn{3}{|l|}{ Textbooks \& Materials } \\
\hline \multicolumn{3}{|l|}{ Methods \& Approaches } \\
\hline \multicolumn{3}{|l|}{ Instruction Time } \\
\hline \multicolumn{3}{|l|}{ Management \& Evaluation } \\
\hline $\begin{array}{l}\text { Communication between different departments } \\
\text { (Curriculum, assessment, training, supervision, teachers, .. } \\
\text { etc. of English Language) }\end{array}$ & & \\
\hline
\end{tabular}

\section{Comments:}

